\title{
Crystallization by particle attachment (CPA) in biominerals over 550 million years
}

Pupa U.P. A. GILBERT ${ }^{1}$, SusAnNAH M. PORTER ${ }^{2}$, CHANG-YU SUN ${ }^{1}$, SHUHAi XIAO ${ }^{3}$, BRANDT M. GIBSON ${ }^{4}$, NOA SHENKAR ${ }^{5}$, ANDREW H. KNOLL ${ }^{6}$

${ }^{1}$ Department of Physics, UW-Madison, WI 53706

${ }^{2}$ Department of Earth Science, UC-Santa Barbara, CA 93106

${ }^{3}$ Department of Geosciences, VA Tech, VA 24061

${ }^{4}$ Department of Earth and Environmental Sciences, Vanderbilt U, Nashville, TN 37235, USA

${ }^{5}$ School of Zoology, and Steinhardt Museum of Natural

History, Tel-Aviv U, 69978 Israel

${ }^{6}$ Department of Organismic and Evolutionary Biology,

Harvard U, Cambridge, MA 20138, USA

Diverse marine organisms form their biominerals using crystallization by particle attachment (CPA)(1) of the same two amorphous calcium carbonate (ACC) precursor phases, which then crystallize into either calcite or aragonite, respectively, in echinoderms (2-4) or mollusk shell nacre (5) and coral skeletons (6), as revealed by difficult, lengthy, synchrotron spectromicroscopy experiments (7).

Much simpler SEM experiments show that when the biominerals are formed via attachment of ACC nanoparticles, they also appear nanoparticulate after cryofracturing, with nanoparticle size in the 50-400 $\mathrm{nm}$ range. The latter is thus a proxy for the former. Vaterite crystals from tunicate spicules, which do not form via ACC (8), do not exhibit nanoparticulate cryofracture-figure. Having validated this proxy on well-known, modern biominerals, we used nanoparticulate texture as a proxy for crystallization by CPA in modern and fossil biominerals.

We find that CPA is convergent: it has evolved independently in diverse phyla, including the oldest know animal fossil, the Ediacaran Cloudina (550 Ma), Cambrian (500 Ma) shelly fossils, nacre from the Ordovician (450 Ma), the Cretaceous (100 Ma), the Miocene (13 Ma) and modern (0 Ma) mollusks.

1. JJ De Yoreo 2015 10.1126/science.aaa6760

2. Y Politi 2008 DOI: $10.1073 /$ pnas. 0806604105

3. CE Killian 2009 DOI: $10.1021 /$ ja907063z

4. YUT Gong 2012 DOI: $10.1073 /$ pnas. 1118085109

5. RT DeVol 2015 DOI: $10.1021 /$ jacs.5b07931

6. T Mass 2017 DOI: 10.1073/pnas. 1707890114

7. T Parasassi 1991 DOI: $10.1080 / 09553009114550061$

8. B Pokroy 2015. DOI: 10.1021/acs.chemmater.5b01542 